\title{
Aporías de la sustentabilidad capitalista
}

\author{
Antonio Elizalde Hevia \\ Revista Polis, Santiago, Chile. Email: antonio.elizalde@gmail.com
}

\begin{abstract}
Resumen: El artículo apunta a demostrar que la sustentabilidad capitalista es una imposibilidad dado que en la naturaleza del capitalismo está la necesidad de crecimiento sin límites. Se diseñan algunos futuros escenarios posibles para la humanidad y se señala que el desconocimiento de las escalas, de las temporalidades y de los límites de la condición humana ha permitido construir un imaginario plagado de mitos, creencias y tendencias que nos está conduciendo hacia un verdadero suicidio colectivo.
\end{abstract}

Palabras clave: escenarios, escalas, temporalidades, límites, imaginario

\section{Aporias of capitalist sustainability}

Abstract: The article aims to demonstrate that capitalist sustainability is an impossibility since in the nature of capitalism is the need for unlimited growth. Some future scenarios for humanity are here designed and its pointed out that the lack of knowledge about scales, temporalities and of the limits of human condition has allowed to raise up an imaginary vision full of myths, beliefs and trends that are driving us towards a true collective suicide.

Keywords: scenarios, scales, time scales, boundaries, imaginary

\section{Aporias da sustentabilidade capitalista}

Resumo: O artigo tem como objetivo demonstrar que a sustentabilidade capitalista é uma impossibilidade pois na natureza do capitalismo está a necessidade de crescimento ilimitado. Desenham-se alguns cenários futuros para a humanidade e observa-se que o desconhecimento das escalas e temporalidades e dos limites da condição humana tenham permitindo construir um imaginário cheio de mitos, crenças e tendências que estão impulsionando-nos para um verdadeiro suicídio coletivo.

Palavras-chave: cenários, escalas, escalas de tempo, limites, imaginários

$$
* * *
$$

Aporía. (Del griego aporia, dificultad de pasar) Dificultad lógica que presenta un problema especulativo. (Diccionario de la Lengua Española, RAE, XXI edición) 


\section{Introducción}

Nuestra mirada sobre la realidad se constituye a partir de mapas que describen un tipo de territorio que, si bien no se corresponde totalmente con el tipo de vivencias que constituyen nuestro operar en el mundo, nos resultan extremadamente seductores, por el escaso nivel de exigencia y rigor que nos demanda su aceptación. Sin embargo, gran parte de dichos mapas son meras ilusiones que nos han ido domesticando, correspondiéndose con una concepción del universo y del mundo en que vivimos de gran eficiencia, para mantener el sistema de dominación que se nos ha ido imponiendo.

Es limitada la capacidad crítica que hemos desarrollado para cuestionar las visiones dominantes en nuestro imaginario colectivo y que son producto del paradigma dominante hasta el día de hoy en el mundo de las ideas. Parte sustantiva de esta visión sostiene la existencia de un mundo conformado por ámbitos o dimensiones relativamente autónomas entre sí, el cual existe como una realidad "objetiva" exterior a los sujetos, a la cual se puede acceder por medio del desarrollo de las "adecuadas" aproximaciones conceptuales y metodológicas, particulares y propias de cada disciplina científica. Así entonces, se opera con la creencia en la posibilidad de acceder a un conocimiento universal y objetivo de la realidad, a una visión única y verdadera de las cosas, suponiendo que las diferencias de visiones, de afirmaciones y de juicios respecto a la existencia responden a 'insuficiencia’ de conocimiento y de objetividad.

Esta concepción es profundamente errónea, y es imprescindible su superación para poder avanzar hacia una concepción sobre nosotros mismos y nuestro papel en el universo, más integrada y realista, menos destructiva y más amorosa.

\section{Un breve diagnóstico del mundo actual}

El mundo en que vivimos y que hemos llegado a construir dista bastante de lo que fueron los ideales de la Ilustración, resumidos por la Revolución Francesa, en los principios de Libertad, Igualdad y Fraternidad. Hay diversos autores que nos hablan de las promesas incumplidas de la Modernidad. Hemos llegado a una sociedad en la cual el mal llamado "mercado global” es, como lo sostiene Fritjof Capra, «una red de máquinas programadas de acuerdo con el principio fundamental de que ganar dinero tiene que primar sobre los derechos humanos, la democracia, la protección del medio ambiente o cualquier otro valor.» (2003:330)

Se ha instalado en el mundo un modelo de bienestar, basado en la posesión-acumulación de bienes y en una moral del disfrute a través del consumo obsolescente, individualista y acelerado, los cuales están indisolublemente ligados a la depredación de la formas de vida existentes y 
a la producción de desechos cada vez mayores, en el planeta que habitamos y es nuestro único hogar. Esta sociedad del turboconsumo y del hiperconsumidor, como la llama Lipovestky (2007), parece absolutamente incapaz de universalizar a todos los humanos el bienestar que provee a unos pocos. De allí que amén de inviable por la existencia de los límites planetarios, aparece como una sociedad injusta ya que no es capaz de «permitir el desarrollo igual de las capacidades básicas de todos los seres humanos.» (Cortina, 2002:223). Es además una sociedad que crea artificialmente necesidades y que aliena metódicamente a la mayor parte de la población, mediante el uso de productos superfluos e impulsando un derroche sistemático y permanente, profundizando así una ética hedonista narcisista individualista para posibilitar la penetración cultural del pensamiento neoliberal en las conciencias sin responsabilidad para con el futuro y que también alimenta la ilusión de alcanzar una forma de vida imposible de universalizar sin que colapse el ecosistema planetario.

\section{El mismo Capra señala que:}

«En la sociedad capitalista contemporánea el valor fundamental de ganar dinero va de la mano con la glorificación del consumo material. Un torrente incesante de mensajes publicitarios refuerza en el público la ilusión de que la acumulación de bienes materiales es el camino directo a la felicidad, el verdadero propósito de nuestras vidas. Los Estados Unidos de América proyectan su tremendo poder al resto del mundo, con el objetivo de mantener a toda costa las condiciones óptimas para la perpetuación y la exacerbación de la producción.» (2003:331)

\section{Y continúa afirmando que:}

«La meta principal de este vasto imperio con su abrumadora superioridad militar, su impresionante panoplia de servicios de inteligencia y su posición dominante en ciencia, tecnología, medios de comunicación y entretenimiento no consiste en expandir su territorio, ni en promover la libertad y la democracia, sino en garantizarse el libre acceso a los recursos naturales y la apertura total de los mercados mundiales a sus productos. Consecuentemente, la retórica política estadounidense pasa con facilidad de la "libertad" al "libre comercio" y a los "mercados libres". La libertad de movimiento de bienes y capitales se equipara al utópico ideal de libertad humana al mismo tiempo que la adquisición de bienes materiales se presenta como un derecho humano fundamental, o incluso casi como una obligación.» (2003:332)

De una manera muy explícita esto lo reconoce Friedrich Hayek, uno de los principales exponentes del pensamiento neoliberal en Entrevista publicada en El Mercurio el 19 de Abril de 1981, cuando señala que: «Una sociedad libre requiere de ciertas morales que en última instancia se reducen a la mantención de vidas: no a la mantención de todas las vidas porque 
podría ser necesario sacrificar vidas individuales para preservar un número mayor de otras vidas. Por lo tanto, las únicas reglas morales son las que llevan al 'cálculo de vidas': la propiedad y el contrato.»

Franz Hinkelammert sostiene enfáticamente que este sistema desconoce la principal de las eficiencias, cual es la eficiencia de la reproducción de la vida y que requerimos desoccidentalizar el mundo...»eso implica reconocer que el mundo es el mundo de la vida humana en la cual todos tienen que poder vivir. Este reconocimiento constituye la superación de Occidente.» (1989:12)

Sin embargo, para lograr esta desoccidentalización es necesario tener en cuenta aquello que Zygmunt Bauman nos señala:

«El liberalismo de hoy se reduce al simple credo de "no hay alternativa”. Esta política premia y promueve el conformismo... El arte de la política, cuando se trata de política democrática, se ocupa de desmontar los límites de la libertad de los ciudadanos para permitirles establecer, individual y colectivamente, sus propios límites, individuales y colectivos. Esta segunda parte de la proposición es la que se ha perdido. Todos los límites son ilimitados. Cualquier intento de autolimitación es considerado el primer paso de un camino que conduce directamente al gulag, como si no existiera otra opción más que la de la dictadura del mercado y la del gobierno, como si no hubiera espacio para los ciudadanos salvo como consumidores.» (2001:12)

\section{Y agrega a continuación:}

«la libertad individual solo puede ser producto del trabajo colectivo (solo puede ser conseguida y garantizada colectivamente). Hoy nos desplazamos hacia la privatización de los medios de asegurar-garantizar la libertad individual; si esa es la terapia de los males actuales, está condenada a producir enfermedades iatrogénicas más siniestras y atroces (pobreza masiva, redundancia social y miedo generalizado son algunas de las más prominentes). Para hacer aún más compleja la situación y sus perspectivas de mejoría., pasamos además por un período de privatización de la utopía y de los modelos del bien (con los modelos de «vida buena» que emergen y se separan del modelo de sociedad buena).» (2001:15)

\section{Escenarios posibles}

Vivimos tiempos cruciales para la humanidad. Podemos transitar dependiendo de lo que hagamos hacia varios escenarios posibles.

Uno de ellos, es el de la mantención del capitalismo, en sus diversas versiones, la occidental y también la china, incorporando medidas paliati- 
vas o mitigadoras de su sistemática y persistente destrucción del medio ambiente y de las relaciones socialmente construidas, impulsando una economía verde, apoyada, como lo señala Silvia Ribeiro ${ }^{1}$ en tres grandes pilares:

«a) una mayor mercantilización y privatización de la naturaleza y los ecosistemas, integrando sus funciones como "servicios" a los mercados financieros; b) la promoción de nuevas tecnologías y la vasta expansión del uso de biomasa; y c) un marco de políticas que permitan y premien todo eso, es decir lo que los gobiernos y las sociedades deberíamos hacer para que las empresas puedan hacer ganancias con los dos anteriores.»

Un escenario como éste postergaría transitoriamente los problemas y posiblemente llevaría a consolidar un segundo escenario, del agravamiento previsto del proceso de calentamiento global, con su secuela de inundaciones, sequías, escasez de agua, desertificación, derretimiento de glaciares, elevación del nivel de los océanos, etc. Los conflictos sociales y políticos que se originarán como producto de estos fenómenos geoambientales llevarán al surgimiento de conflictos endémicos cuya solución política puede ser el surgimiento de un absoluto control de los recursos en disputa para asegurarlos a las minorías que los han controlado históricamente, mediante la imposición militar del control por parte de las potencias principales sobre los recursos críticos.

Una derivación de este escenario o escenario complementario, será el surgimiento del ecofacismo en los países centrales, con características parecidas a lo que fue el fenómeno nacional socialista. Las manifestaciones cada vez más evidentes de la crisis ambiental y social (calentamiento global, disminución de la seguridad alimentaria, desplazamientos masivos de poblaciones, encarecimiento de los alimentos, desempleo generalizado, aumento de la criminalidad organizada e inseguridad creciente de la población, entre otros problemas), permitirán el surgimiento de discursos nacionalistas xenófobos en todos los países receptores de migración, buscando culpar a todo tipo de minorías de los problemas existentes, dando así curso a la aparición de organizaciones políticas de carácter facista quienes buscarán acceder al poder político impulsando programas de control del uso y consumo de los recursos naturales, de restricción de las libertades públicas y de suspensión incluso del ejercicio de derechos ciudadanos.

Desde este escenario es posible que se transite, entonces, hacia un tercer escenario, es el de la destrucción mutuamente asegurada. El agravamiento de los problemas por la incapacidad del sistema de frenar la codicia del capital y de producir en un corto período histórico de un cambio cultural profundo, generará un nuevo conflicto bélico, esta vez de carácter global, por la disputa del control de los recursos naturales cada vez más escasos, conflicto en el cual posiblemente se hará uso de armamento nuclear o de armas de destrucción masiva. Los vencedores de ese conflicto ¿si los hay?: tendrían que reconstruir todo (incluso su propia condición humana), 
en las escasas áreas del planeta que hayan quedado al margen de la radiación nuclear.

Un cuarto escenario, el deseable, sería la realización de un profundo cambio de conciencia de la humanidad que permita realizar profundas transformaciones culturales, sociales, políticas y económicas, renovando de esa manera las instituciones y la moralidad hegemónica, para transitar hacia caminos no recorridos pero tremendamente promisorios, en los cuales el conjunto de los seres humanos, tendremos mucho que aprender y que aportar.

\section{¿Racionalidad o patología?}

El operar del mercado globalizado se articula a partir del desprecio de lo local, de lo singular, de lo específico, de lo concreto; en síntesis, del desprecio de la condición humana. La historia nos muestra como en el paso desde la producción artesanal a la producción industrial el producto

El eje articulador del episteme dominante es la búsqueda del mínimo común denominador, de la homogeneización, de la uniformación; la ciencia occidental está orientada preferentemente hacia las medidas de tendencia central: moda, mediana, promedio. Y se ha desentendido de la desviación, de la varianza, de la diferenciación. Ha construido así un episteme de la normalidad, de la norma, de la normalización que desprecia la singularidad. co Varela:

Occidente es abstracción, como muy agudamente lo señaló Francis-

“..."Racionalista”, “cartesiana” u “objetivista”: estos son algunos de los términos que se utilizan hoy en día para caracterizar la tradición dominante en la que hemos crecido. Sin embargo, cuando se trata de re-formular el conocimiento y la cognición, considero que el término que mejor se adecua a nuestra tradición es abstracta: no hay palabra que caracterice mejor a las unidades de conocimiento que han sido consideradas más “naturales”. La tendencia a abrirnos paso hasta la atmósfera pura de lo general y de lo formal, de lo lógico y lo bien definido, de lo representado y lo planificado, es lo que le confiere su sello característico a nuestro mundo occidental.” (1996:13)

Inmanuel Wallerstein, a su vez, señala que el camino de la necesaria racionalidad material que deberemos recorrer es un camino que:

“Involucra no solamente un nuevo sistema social, sino también nuevas estructuras de conocimiento, en las que la filosofía y las ciencias no podrán seguir divorciadas, y retornaremos a la epistemología singular en pos del conocimiento utilizada con anterioridad a la creación de la economía-mundo capitalista.” 
Las más importantes instituciones de la modernidad buscan sistemáticamente construir esa normalización, pues mediante ella se logra una "mayor eficiencia y productividad". El ejemplo más conspicuo es la escolarización, mediante ella se persigue construir un niño promedio, ajustado totalmente a las normas disciplinantes de los procesos educativos, de modo de poder alcanzar de ese modo las metas que las políticas educativas dominadas por una obsesión cuantofrénica buscan lograr. Cada vez importa menos la educación entendida como proceso mediante el cual se ayuda al educando a desplegar sus propias potencialidades, para priorizar las búsqueda del desarrollo de competencias que le permitan competir en el mercado laboral, aunque hoy los mercados laborales valorizan como lo señala Sennett: "un individuo que está constantemente adquiriendo nuevas habilidades, cambiando su "base de conocimiento"." (2006:43)

Un destacado epistemólogo como Paul Feyerabend hizo la siguiente descripción:

"La educación científica, como hoy día se entiende... simplifica la ‘ciencia' simplificando a sus participantes: en primer lugar se define un dominio de investigación. A continuación, el dominio se separa del resto de la historia (la física, por ejemplo, se separa de la metafísica y de la teología) y recibe una lógica propia. Después un entrenamiento completo en esa lógica condiciona a quienes trabajan en dicho dominio. Con ello se consigue que sus acciones sean más uniformes y al mismo tiempo se congelan grandes partes del proceso histórico. Hechos estables surgen y se mantienen a pesar de las vicisitudes de la historia. Una parte esencial del entrenamiento que posibilita la aparición de tales hechos consiste en el inhibir las intuiciones que pudieran llevar a hacer borrosas las fronteras. La religión de una persona, por ejemplo, o su metafísica, o su sentido del humor... no debe tener el más mínimo contacto con su actividad científica. Su imaginación queda restringida, e incluso su lenguaje deja de ser el suyo propio.” (1986:3-4)

Hay instalado muy profundamente en nosotros algo que podríamos llamar el “Síndrome del Control”, cual es la pretensión en un contexto de incertidumbre como es el operar de la vida, establecer mecanismos que nos provean de certezas, de seguridad. Llega a tal punto esta búsqueda de seguridad que en la persecución de ella terminamos cometiendo las peores atrocidades, que niegan en muchos casos los valores o principios en función de los cuales articulamos nuestra identidad. Un cuento de Borges da cuenta de una manera magistral de esta obsesión, trata sobre aquel emperador de un próspero imperio que quiso que sus geógrafos hiciesen un mapa perfecto del territorio. El pueblo entero, todos los súbditos, tuvieron que abocarse a dicha tarea. Para ello debieron dejar de cultivar, de cosechar, de producir, en síntesis: de vivir. Ellos cumplieron la tarea con tanta eficiencia que terminaron por obtener un mapa que coincidía, en todos los puntos posibles, con el territorio en cuestión. Una vez obtenido este mapa absoluto, deviene absurdo, puesto que la mejor expresión real del territorio es el territorio en 
sí, cuya realidad supera la de cualquier mapa. Se produce así la saturación feliz de un modelo en su propia realidad, la paradoja que Jorge Luis Borges, ha imaginado para explicar el éxtasis de lo real.

\section{Desconocimiento de las escalas}

La escala humana (la escala en la cual podemos asignar sentido) ha sido pulverizada por la globalidad, por la globalización que ha transformando el conjunto de los diversos territorios donde se desplegó la existencia humana hasta ahora, con su diversidad de lenguas y culturas en un solo mundo, en un planeta único, en un territorio global. Es la unificación del mundo, la globalización, la mundialización del mundo, todo ello mediante una globalización perversa, como la denominó Milton Santos.

Pero es este un espacio unificado, mucho más allá de la escala de la comprensión humana, de la asignación de sentidos y de las responsabilidades subyacentes a ello, de la escala en la cual podemos vivenciar el impacto o resultado de nuestro operar como una retroalimentación que nos permite evaluar nuestra propia conducta, y consecuentemente valorarlo como algo positivo o negativo. Hemos transgredido la escala de la acción humana y hemos llegado a instalarnos en una situación que podríamos denominar una falacia transescalar. Llegamos así prácticamente a una situación en la cual nadie es (o se siente) responsable de nada. De allí la permanente necesidad casi infantil de nuestra sociedad actual de vivir buscando y construyendo chivos expiatorios, demonios, partidarios del mal para convertirlos en enemigos a los cuales culpar de los propios errores y omisiones.

El ejemplo más conspicuo de esta falacia transescalar es la megaciudad, las metrópolis urbanas habitadas por varios millones de seres humanos, donde se ha producido una agregación extrema que ha conducido a su desnaturalización. Las ventajas de la vida citadina impiden de hecho la condición ciudadana, de allí que ya no sea posible hablar de ciudadanos y sea necesario hablar de urbanitas. Los tiempos de traslado al interior de esas megapolis se van haciendo cada vez mayores en la medida en que la ciudad crece. Como se lo escuché decir a Mariano Vásquez Espí: el problema ambiental es la ciudad, y la solución al problema ambiental es acercarnos a la producción de alimentos.

"Nuestras ciudades, en 2007 albergaban a la mitad de la población mundial, y consumían bastante más del 80\% de los recursos agotables del planeta.” (2008:180)..."El creciente transporte a larga distancia, imprescindible sólo para la jerarquía de conurbaciones, implica un aumento del consumo de recursos minerales (combustibles fósiles y otros) que no puede traducirse en aumento de organización: simplemente es tiempo perdido (y el tiempo puede emplearse como una medida universal para la contabilidad de los recursos, véase Valero, 1998). Y como duplicar la velocidad significa, como poco, cuadruplicar la energía demandada por un modo de transporte con- 
creto, y puesto que las conurbaciones modernas han aumentado 10 , $100,1.000$ veces las distancias respecto a aquella ciudad agrícola del neolítico (y por tanto la velocidad), se sigue un aumento del consumo energético de 100, 10.000, 1.000.000 de veces, como mínimo. Por supuesto que, en el corto plazo, es posible cambiar un modo de transporte por otro más eficiente (las caravanas de Marco Polo por las carabelas de Colón; los correos aéreos por Internet), pero se trata tan sólo de una maniobra de distracción, a la larga el tiempo perdido vuelve a aumentar según la distancia aumenta. Por más que popularmente se hable de crisis energética, nuestra crisis es de minerales y tiempo escasos. Es por ello que la globalización sigue siendo bastante parcial después de todo: el grueso del consumo sigue produciéndose a corta distancia pues de otro modo los costes habrían llegado a ser insoportables: el comercio global no alcanza ni a la mitad de los intercambios mundiales. Es por ello también que las ciudades globales albergan legiones de desposeídos y explotados, en barrios marginales: las áreas de extracción se sitúan tan cerca como sea posible, entrelazadas de forma intricada con las áreas de consumo y disfrute: las bolsas de pobreza aparecen por ello cualquiera que sea la escala de nuestra mirada: países, regiones, ciudades, barrios, calles. En consecuencia, las peculiaridades geográficas del metabolismo urbano impiden a las ciudades globales ofrecer a toda su ciudadanía las ventajas de su posición en la jerarquía: cada conurbación formaliza su propia jerarquía local de centros de disfrute y consumo conectados a periferias de extracción o vertido; las conurbaciones se desgajan en zonas especializadas, sus poblaciones se segregan según cual haya sido la posición que les cayó en suerte en la jerarquía local, la diversidad de las periferias urbanas disminuye y, sobre todo en ellas, la complejidad necesaria a la organización cooperativa de la antigua ciudad amurallada se desvanece, siendo sustituida por una sociedad simplificada, organizada por la simple competencia, incluyendo violentos sucesos de ingobernabilidad.” (2008:194)

Se ha construido una escala global del operar de los procesos de crecimiento capitalista para la cual nada importan los territorios y las personas que los habitan, las instituciones que se hayan dado o la cultura que poseen. Hemos llegado a la abstracción en la cual el territorio, ya no importa nada:

"La economía mundial ha dejado la tierra y ha subido al cielo, donde ya no importa el espacio [...] las grandes ciudades, donde se realiza el trabajo de inversión y coordinación, se han hecho incluso más importantes en la era global.” (Sennett, 2006:41)

Todo ello queda absolutamente subordinado a los intereses del capital, que todo lo devora, todo lo procesa, todo lo destruye. Lo político y económicamente correcto es hacer lo que convenga al capital, así sea con- 
denar a la hambruna o al desplazamiento a poblaciones completas, no solo de localidades sino incluso de regiones de un país.

Y la lógica del capital es crecer, y continuar creciendo para mantener (si no es posible incrementar) la tasa de ganancia. El ADN del capital es crecer indefinidamente, de allí su incompatibilidad con la sustentabilidad, no hay posibilidad de un crecimiento sustentable. El crecimiento es por naturaleza insustentable. De allí que la naturaleza le ponga límites en su código genético a todas las formas vivas.

Sin embargo, hay quienes creen que es posible continuar creciendo indefinidamente y que frente a los límites que nos pone nuestro planeta, en algún punto los recursos que se vayan agotando podrán ser sustituidos por otros gracias a los avances de la tecnociencia. Realizándose de ese modo el axioma de la sustituibilidad perfecta de los factores productivos: teniendo el capital para hacerlo todo es posible y no hay problema. El modelo propio de la "ciencia económica" funciona si o si pues como lo ha sostenido Robert Solow: "Si puede lograrse con gran facilidad la sustitución de los recursos naturales por otros factores, en principio no habría "problemas". En este caso, el mundo puede seguir adelante sin recursos naturales, de modo que su agotamiento es sólo un acontecimiento, no una catástrofe”. (1994:94).

Desconocen obviamente los cálculos hechos por Isaac Asimov (1973), quien señaló:

"Si la población terrestre continúa duplicando su número cada treinta y cinco años (como lo está haciendo ahora) cuando llegue el año 2.600 se habrá multiplicado por 100.000 (...) ¡La población alcanzará los 630.000.000.000! Nuestro planeta sólo nos ofrecerá espacio para mantenernos de pie, pues se dispondrá únicamente de 3 $\mathrm{cm} 2$ por persona en la superficie sólida, incluyendo Groenlandia y la Antártida. Es más, si la especie humana continúa multiplicándose al mismo ritmo, en el 3.550 la masa total de tejido humano será igual a la masa de la Tierra.” (1973).

Pese a lo anterior, hay quienes sostienen que incluso ese escenario de hacinamiento planetario sería bueno y conveniente para impulsarnos así a desarrollar la conquista galáctica. Sin mebargo, frente a esta ilusión el mismo Asimov señala:

"Si hay quienes ven un escape en la emigración a otros planetas, tendrán materia suficiente para alimentar esos pensamientos con el siguiente hecho: suponiendo que hubiera 1.000.000.000.000 de planetas habitables en el Universo y se pudiera transportar gente a cualquiera de ellos cuando se estimara conveniente, teniendo presente el actual ritmo de crecimiento cuantitativo, cada uno de esos planetas quedaría abarrotado literalmente y sólo ofrecería espacio para estar de pie allá por el año 5.000. ¡En el 7.000 la masa humana sería igual a la masa de todo el Universo conocido!” 
No obstante hay muchos (la tecnoburocracia, los multimillonarios, los economistas neoliberales, las multinacionales, los científicos al servicio de estas, entre muchos otros), o en la descripción más afinada de Sennett,

“determinadas clases de burocracias económicas. Son grandes, venden acciones ellas mismas y son capaces de obtener beneficios de la tecnología avanzada... Son quienes están dedicados a los: "servicio financieros, legales y de seguros, la producción y el transporte globales [...] el diseño industrial, la publicidad y el marketing, los medios de comunicación y el diseño por ordenador.” (2006:43).

Estos son quienes confiando en el poder de la ciencia y la tecnología, y creyendo ciegamente en el mercado como asignador de recursos, no sólo piensan que es posible sino que incluso hacen lo posible para que la economía siga creciendo, a fin de satisfacer la naturaleza intrínseca del capital (su insaciabilidad y codicia): incrementar o al menor mantener su tasa de ganancia, para lo cual le es necesario seguir explotando lo que sea posible. Su lógica es convertir todo en objeto de ganancia, para ello todo lo que es abundante lo torna escaso para poder así asignarle precios que hacen posible mercantilizarlo. El crecimiento permanente está en su ADN, no puede dejar de crecer. Su voracidad no tiene límites y de ese modo nos está conduciendo hacia un suicidio colectivo.

Frente a esa mirada recurro nuevamente a Asimov quien afirmó que:

"Evidentemente, la raza humana no puede crecer durante mucho tiempo al ritmo actual, prescindiendo de cuanto se haga respecto al suministro de alimentos, agua, minerales y energía. Y conste que no digo «no querrá», «no se atreverá» o «no deberá»: digo lisa y llanamente «no puede».

Y hasta ahora solo hemos usado las estimaciones hechas por Asimov para una tasa de crecimiento anual de 2 a 3 por ciento, la de crecimiento demográfico. ¿Qué pasa cuando esas proyecciones se hacen para el crecimiento de la economía a tasas como las que ha tenido China en las décadas recientes, entre 8 a 10 por ciento, duplicando de ese modo su producto en menos de una década. Llegamos a la situación que algunos han denominado la gran aceleración del siglo XX

- La población humana creció de 1,6 mil millones a 6 mil millones : casi 4 veces

- La economía mundial creció 14 veces

- El uso de energía creció 16 veces

- El uso del agua creció 9 veces

- El incremento del bióxido de carbono fue de 13 veces

- Las emisiones industriales subieron 40 veces

En este cuadro de crecimiento sin frenos, los autos y las reses pueden ser considerados los íconos del consumo del siglo XXI. Por cada dos 
humanos que nacen al año se construye un auto. Al 2010 parque vehicular alcanzó los mil millones. Producen el 15\% de los gases que contaminan la atmósfera y cada uno en su construcción produce entre 15 a 20 toneladas de residuos.

Las reses pesan más que todos los seres humanos. Hacia 2001 eran más de 1530 millones emitiendo metano y óxido nitroso, gases que inducen al calentamiento global.

La expansión de la ganadería vacuna es la principal causa de destrucción de millones de hectáreas de selvas tropicales.

Sin embargo, hoy se plantea en el discurso de la "economía verde" como la gran panacea la producción de biocombustibles (etanol) para sustituir el petróleo, a partir de la caña de azúcar, de la palma africana u otros cultivos. Asimismo se produce soja para alimentar ganado ovino que solo pueden consumir los ricos del planeta. Y el mijo, el sorgo, el maíz y el trigo bases fundamentales de la dieta de los pobres se baten en retirada. De modo tal que el real dilema político y moral al cual nos estamos enfrentando será: o alimentamos reses y automóviles o alimentamos seres humanos. Y al parecer conforme muestran los datos presentados recientemente por la FAO, los humanos van perdiendo. Ello en razón de que los alimentos han sido transformados también en objeto de especulación financiera y por lo tanto los precios de los alimentos están encareciéndose de forma acelerada.

\section{Desconocimiento de las temporalidades}

El operar humano instituyó la historia, la visión de un tiempo pasado y de un tiempo futuro. Hoy, sin embargo, se ha construido el tiempo único. El tiempo dominante ha impuesto su valoración de los ritmos, ha ordenado la polifonía rítmica de la vida en la partitura única del tiempo del dinero, del tiempo de la acumulación. Incluso se han diseñado formas mediante las cuales consumir el tiempo futuro. Estamos expropiando a las generaciones venideras su bienestar potencial como producto de esta adicción aceleratoria que caracteriza al mundo actual.

La permanente aceleración del ritmo de vida está conduciendo a la humanidad a un callejón sin salida, ya que nuestra condición humana requiere de tiempo para construirse. Nuestra humanidad no es algo genético, es algo cultural, esto significa que es una condición que requiere de un tiempo para su despliegue. A diferencia del resto de los seres vivos cuyo transcurrir vital están determinado en su biología, nosotros requerimos del tiempo para poder desplegar nuestra historia vital, requerimos de tiempo para aprender a ser humanos, para aprender un lenguaje, para aprender a vivir en común, para adquirir las destrezas y competencias que nos permitan procurarnos los recursos que necesitamos para vivir, para enriquecer nuestra identidad con la presencia de la otredad, para transitar desde la heteronomía a la autonomía. 
Sin embargo, todo apunta hacia la reducción del espacio temporal en el cual se instala la cultura, donde ella se hace manifiesta, que es el tiempo o distancia fáctica transcurrida entre el surgimiento del deseo y su satisfacción. La sociedad del hiperconsumo y del turboconsumidor, construido en las sociedades capitalistas de consumo masivo, busca reducir esa distancia fáctica o intervalo temporal, ofreciendo a cambio el consumo instantáneo e inmediato. Pensemos, por ejemplo, en la cultura del té propia de Oriente con su ritual y tiempo requerido para su preparación versus el té en bolsitas propio de Occidente, o el tiempo necesario para la preparación de un asado al estilo patagónico versus las hamburguesas de MacDonald.

\section{Desconocimiento de los límites de la percepción humana}

Lo paradojal, sin embargo, es que hay un tiempo creciente gastado en elegir, en decidir o discriminar frente a una oferta de bienes casi inconmensurable. Es notable al respecto el incremento del peso de los periódicos durante el fin de semana. Hojas y cuadernillos, revistas, guías de todo tipo y una cantidad impresionante de (des)información desconociendo los límites de la capacidad humana para procesarla.

\section{$\mathrm{Al}$ respecto Zygmunt Bauman señala que:}

"Según los cálculos de Ignazio Ramonet, durante los últimos treinta años, en el mundo se ha producido más información que durante los 5 mil años anteriores, mientras que "un solo ejemplar de la edición dominical del New York Times contiene más información que la que una persona culta del siglo XIX consumía durante toda su vida”.” (2007: 61)

Pero continúa afirmando algo que nos concierne mucho más directamente a quienes escribimos, investigamos y reflexionamos sobre estos temas, citando a Eriksen,

"quien afirma que: "más de la mitad de todos los artículos periodísticos publicados en materia de ciencias sociales nunca son citados", lo que sugiere que más de la mitad de la información producida por los investigadores no es leída nunca por nadie excepto por sus "colegas revisores”, los correctores y editores.” (2007: 61-62)

Algo similar es lo que señala Sennett cuando afirma:

"Me refiero al iPod, con capacidad para almacenar y reproducir diez mil canciones de tres minutos. Pero ¿cómo hará uno para escoger las diez mil canciones, o de dónde sacará tiempo para bajarlas? ¿Cuáles serían los principios de selección de las quinientas horas de música que contiene esa cajita blanca? ¿Acaso sería posible recordar las diez mil canciones a fin de elegir una en particular que se deseara oír en un momento determinado? (Esta proeza de la memoria 
humana implicaría, en el campo de la música clásica, la capacidad de saber de memoria prácticamente todas las obras de Juan Sebastián Bach.)." (2006:131)

De allí entonces que lo que se va construyendo es una realidad donde es cada vez más difícil proveer de sentido a esa creciente masa de informaciones distribuida con una velocidad también creciente, o discriminar lo verdaderamente relevante para cada cual, lo que dificulta generar relatos, órdenes, secuencia de desarrollo, y todo se torna irrelevante, nimio o trivial, de modo tal que las cosas e incluso las personas son experimentadas como insustanciales. Nada merece una atención preferencial por encima de ningún otro.

Y la paradoja es que como lo sostiene Sennett:

“...el poderoso atractivo comercial del iPod consiste precisamente en tener más de lo que una persona podría usar jamás. Parte de ese atractivo reside en una conexión entre potencial material y capacidad potencial de un individuo.” (2006:132)

Y esto que hemos señalado respecto a la información o la música preferida se da en prácticamente todos los planos de la existencia. Ya nada nos asombra. Nos hemos insensibilizado a tal punto que incluso las peores tragedias, aberraciones o atrocidades nos parecen normales. Vivimos en una suerte de creciente embotamiento moral. De allí entonces que se continúa en la misma senda irremediablemente suicida, a pesar de las evidencias que están al alcance de cualquiera persona medianamente informada.

Según William R. Catton Jr., sociólogo norteamericano, autor del libro Overshoot publicado en 1980 y traducida recién en 2010 al castellano como Rebasados, Fred Cottrel en su libro Energy and Society, publicado por McGraw-Hill, Nueva York ya en 1955 mostraba,

"que se invertía mucha más energía en cultivar cincuenta búshels por 0.40 hectáreas en campos de arroz mediante métodos mecanizados en Arkansas que mediante los cultivos que utilizaban el azadón en Japón. La ilusión de que los procedimientos de Arkansas eran más "eficientes” surgían del hecho de que allí se necesitan menos de dos días-hombre de trabajo humano por acre, en comparación con los noventa días-hombre en Japón. Sin embargo, para conseguir ese ahorro de ochenta y ocho días-hombre de trabajo humano, el granjero de Arkansas tenía que invertir en tractores, combustible para tractores, electricidad y abonos, todo lo cual implicaba una energía equivalente a por lo menos ochocientos díashombre adicionales al esfuerzo. Esta extravagancia en el consumo de energía seria aun más flagrante si el cálculo incluyera la energía utilizada en la construcción, el transporte por barco y la manutención del tractor, el camión, los aparatos eléctrico de bombeo, etcétera.” (2010:85) 
A su vez, Paul A. Samuelson en un artículo publicado en El País, titulado "Adiós al capitalismo de Friedman y Hayek"2 señalaba lo siguiente:

"Los sistemas de mercado no regulados acaban destruyéndose a sí mismos. ¿ ¿Ha llegado el sistema de mercado a su fin? Como persona apegada a los valores tradicionales, espero que no. Mil años de historia económica atestiguan objetivamente lo indispensables que son los sistemas de mercado... ¿¿Qué es entonces lo que ha causado, desde 2007, el suicidio del capitalismo de Wall Street? En el fondo de este caos financiero, el peor en un siglo, encontramos lo siguiente: el capitalismo libertario del laissez-faire que predicaban Milton Friedman y Friedrich Hayek, al que se permitió desbocarse sin reglamentación. Ésta es la fuente primaria de nuestros problemas de hoy. Hoy estos dos hombres están muertos, pero sus envenenados legados perduran.”

Por su parte, Joseph Stiglitz, economista, ex director del BM, Premio Nobel, profesor de la Universidad Columbia, haciendo referencia también al origen de la crisis subprime, sostiene algo similar en un artículo titulado “Capitalistas estúpidos”, publicado en Vanity Fair/Znet:

“El gobierno habló de desarrollo de confianza, pero lo que presentó fue en realidad un timo. Si el gobierno hubiera querido realmente restaurar confianza en el sistema financiero, habría comenzado por encarar los problemas subyacentes - las estructuras deficientes de incentivos y el sistema regulador inadecuado. ¿Hubo una sola decisión aislada que, si hubiera sido revertida, habría cambiado el curso de la historia? Todas las decisiones, incluidas las de no hacer algo, como han sido muchas de nuestras malas decisiones económicas, son consecuencia de decisiones anteriores, una red interrelacionada que va desde el pasado lejano hasta el futuro. La verdad es que la mayoría de los errores individuales se reducen a sólo uno: la creencia en que los mercados se ajustan solos y que el papel del gobierno debiera ser mínimo. Al mirar retrospectivamente a esa creencia durante audiencias en otoño de este año en el Congreso, Alan Greenspan dijo en voz alta: "He encontrado un defecto." El congresista Henry Waxman lo presionó, respondiendo: "En otras palabras, usted ha descubierto que su visión del mundo, su ideología, no era correcta; no funcionaba". "Ciertamente, precisamente," dijo Greenspan. La adopción por EE.UU. - y por gran parte del resto del mundo - de esa filosofía económica defectuosa hizo inevitable que hayamos llegado al lugar en el que nos encontramos actualmente.”

Podemos concluir que el principal desconocimento que experimentamos es el desconocimiento de la complejidad de lo real, es decir el reduccionismo instalado muy profundamente en el imaginario colectivo de Occidente, y ello porque se encuentra impregnado y hegemonizado por el lenguaje economicista. Es el lenguaje de la escasez, que todo lo sobre sim- 
plifica y que opera con una visión crematística, que nos conduce a actuar como necios, “al confundir valor y precio”, como lo señalaba Machado.

\section{El imaginario en las sociedades actuales: sus mitos y creencias. Elementos para una reflexión crítica}

La forma como pensamos el mundo determina las conductas adictivas y suicidas que caracterizan a la sociedad actual. De allí entonces que para efectos analíticos asumamos la siguiente hipótesis: nuestras creencias condicionan nuestras ideas y emociones. Ningún cambio es posible sin modificar las creencias en las cuales nos movemos.

Hay un conjunto de creencias instaladas en el imaginario colectivo de la humanidad por Occidente, por la Ideología del Progreso, por el Capitalismo y por el Desarrollismo, de una manera progresiva y sistemática a lo largo de nuestra historia reciente. ¿Cuáles son algunas de ellas?

\section{Más es igual a mejor}

Los seres humanos actualmente vivos hemos sido socializados en una forma de concebir la vida como un ejercicio permanente de logro de más y más, en una permanente insatisfacción con lo que tenemos, con lo que somos, con lo hecho. Nuestra cultura ha roto con todas las tradiciones del pasado en las cuales se valoraba la mesura, la moderación, la continencia. Por el contrario, hoy se nos exige vivir en una permanente tensión en búsqueda de más y más, como si ello nos fuese sinónimo de mejor.

\section{La tecnología todo lo puede}

La tecnología es el gran mito en el cual tenemos depositada nuestra confianza, un confianza acrítica y casi ciega. Posiblemente porque las generaciones de seres humanos vivos hemos experimentado los enormes beneficios que ella nos ha reportado. Las tecnologías de la salud han permitido prolongar la vida humana en más de una década durante este siglo. Las comunicaciones son hoy posibles con cualquier lugar del mundo. Podemos apreciar la presencia virtual e instantánea de un ser querido que está lejos o viajar de un extremo a otro de un país o del mundo en horas. La tecnología se ha hecho parte constitutiva de nuestra existencia, son tantas las mejoras en nuestras condiciones de vida, tantos los logros obtenidos mediante ella, que inadvertidamente la hemos transformado en un poder casi omnímodo. Pensamos que si hoy algo no es posible la tecnología en algún momento futuro lo hará posible, todo entonces sería cuestión de tiempo. Hay incluso quienes pagan enormes cantidades de dinero para que criogenicen sus cuerpos una vez muertos esperando la ¡¡resurrección tecnológica!! ¡Que ingenuidad! (Esto porque de resucitar, resucitarán viejos y/o enfermos que fue tal como se murieron). 


\section{La competencia es algo natural y nos conduce a ser mejores}

Todo el discurso instalado en el imaginario de la globalización está construido en torno a la competencia, pero en el sentido de competir: competir por los mercados, por los clientes, por los consumidores. Y la competencia conduce a lo contrario de aquello que pretendidamente busca que es: eliminar el monopolio; ya que busca eliminar al competidor y de tener éxito, se llega al competidor único quien al no tener competidores puede hacer lo que se le dé la gana en el mercado, Pero a la vez se confunde competitividad con competencia. Ya no importa tanto ser competente como competitivo. Incluso gran parte de toda nuestra institucionalidad apunta en esa perspectiva, desde pequeños se estimula la competitividad, y no las potencialidades propias de cada ser humano, mediante premios y galardones de diversa índole.

\section{El “éxito" debe ser la principal meta de la vida}

El imaginario actual está articulado en torno a una noción central, "el éxito". Se concibe la existencia humana como predestinada al logro, a la consecución de grandes metas, a la persecución obsesiva del éxito. Es fundamental lograrlo como sea en todos los ámbitos de la existencia. No importa cómo, incluso se piensa que el propio éxito puede tapar los ripios del camino recorrido para llegar a él. Joaquín García Roca nos habla del mito de la cumbre o del éxito. La vida entendida como una ascensión, como un permanente desplazamiento hacia una cumbre, en la cual nos espera el éxito. Pero una vez lograda la conquista de esa cumbre es necesario reiniciar el ascenso hacia otra cumbre, y luego otra y otra. Es el mito de la realización humana. Nos vemos así confrontados permanentemente por el ideal hacia el cual debemos transitar, en una permanente insatisfacción que nos mantiene vivos; la vida concebida como un continuo movimiento. Todos encaminados en busca de ser exitosos, triunfadores, ganadores, cosechando por doquier y acumulando premios, medallas y certificaciones de toda índole, y hay de quien no lo haga: es indigno de ser considerado humano. La vida es concebida como una permanente competencia de todos contra todos, en la cual lo que importa es ganar a como dé lugar.

\section{La única forma de "ser humano" es la propia de Occidente}

Otro mito instalado es el de la normalidad que nos impone una determinada forma de ser humano, la propia de Occidente. Como lo señala Boaventura de Sousa Santos, una cultura local surgida como todas en un determinado momento concreto de la historia humana, en un punto determinado del territorio y en condiciones sociales específicas, ha llegado a constituirse a sí misma en universal, y con ello ha impuesto un determinado modelo de ser humano como el humano genérico y universal. Ello se ha logrado como lo señala Joaquín García Roca con la colaboración de todos (la ciencia, las iglesias, la cultura, las instituciones sociales, las empresas),

«se universalizó lo particular, se niveló la diferencia y se impuso un 
determinado examen de madurez que marcaba la línea divisoria entre la normalidad y la anormalidad, lo correcto y lo incorrecto, lo adaptado y lo inadaptado... «No fueron capaces ayer ni hoy de aprobar este examen las minorías étnicas, los enfermos, las personas con deficiencias, los ancianos, los disidentes, las personas improductivas, los inadaptados: los últimos que se han convertido en las plagas y azotes del siglo XX. Todos ellos ayer y hoy, certifican según la ideología dominante su inferioridad humana, su tara y su degradación. Tenemos el mito adecuado para la más despiadada marginación.» (1990: 5-6)

De ese modo una proporción importante de la humanidad queda relegada a la condición de inviable, incapaz o inepta para transitar hacia la condición de plenitud humana. Hoy incluso se habla de países inviables. De allí a la desechabilidad no hay más que un paso. En la historia de America Latina hubo y aún hay grupos de su población que consideraron a otros sectores como un peligro, una molestia, como desechables y que pagaron e incluso siguen pagando para que se les extermine.

De allí la validez de lo señalado por Franz Hinkelammert, la peor de las calamidades que ha experimentado la humanidad en las décadas recientes ha sido la occidentalizacion del mundo. Sostiene que la sociedad occidental tiene raíces históricas principalmente judeo-cristianas y greco-romanas, raíces que son transformadas y recreadas en la búsqueda de un nuevo sujeto humano, en una relación absolutamente distinta con las estructuras sociales y su transformación. Este proceso está signado por la utopía de la libertad. La sociedad occidental ha hecho de esta utopía su identidad al determinarla con las estructuras sociales. Terminando devorado el sujeto humano de la utopía en nombre de ella por las propias estructuras que persiguen su realización, transformándose así en una utopía destructora. De allí entonces que Hinkelammert sostenga la necesidad de

“...desoccidentalizar el mundo; eso es justamente esta tarea: desoccidentalizar la iglesia, desoccidentalizar el socialismo, desoccidentalizar la peor forma de Occidente cual es el capitalismo, desoccidentalizar la misma democracia. Pero eso implica reconocer que el mundo es el mundo de la vida humana en la cual todos tienen que poder vivir. Este reconocimiento constituye la superación de Occidente.” (1989: 12).

\section{EI mito de la presentabilidad o de la apariencia}

Esta normalidad obsesiva, abusiva e ilusoria nos ha conducido al predominio del aparecer sobre el ser, no importa tanto lo que alguien es como que sea presentable. Hemos llegado así a una ética reducida a estética de la presentabilidad, de los buenos modales, de la conformidad, como si todo pudiera reducirse a una representación teatral en la que a los intereses en juego se les despoja de todo lo que tienen de demasiado feo, inmediato, grotesco y bárbaro. Lo inquietante es ver como la ética de la 
presentabilidad se confunde peligrosamente con una ética de la conformidad o de la convalidación de situaciones cada vez más manipuladas.

Pero a la vez hemos transitado hacia una cultura del engaño y de la simulación, una cultura de la prótesis: lo que no se tiene se agrega, lo que sobra se quita. Todo ello mediante injertos, prótesis, liposucciones, cirugía plástica, implantes, maquillaje, etc.

Hemos llegado a un tipo de consumo que es fundamentalmente conspicuo. En la sociedad actual quien no consume no existe. Se consume para estar presente, para existir, para hacerse visible. De allí hemos llegado a que al final todo es apariencia. Fromm nos habló del dilema entre el ser y el tener. Hoy el dilema es entre el ser y el aparecer. Ya no importa tanto el ser leal, honesto, veraz, generoso, fiel u honrado, como el parecerlo o aparentarlo. En un imaginario instalado en esta creencia ya no hay lugar para el esfuerzo anónimo y silencioso asociado al cumplimiento de deberes de estado (madre o padre, trabajador, estudiante, ciudadano); si hago algo tengo que exhibirlo, pregonarlo, ostentarlo, publicarlo. Importa más el envase que el contenido, lo formal que lo sustantivo.

\section{Tendencias suicidas de la civilización actual}

\section{La ceguera frente a los límites}

La obsesión por el crecimiento ha conducido a la humanidad a desarrollar una casi absoluta ceguera frente a los límites que nos pone la naturaleza. Su origen está anclado en dos razones principales, la primera es la creencia en que nuestro dominio sobre la naturaleza es algo posible de extender indefinidamente gracias a la ciencia y la tecnología, a lo cual ya nos hemos referido. La segunda es la imposibilidad de percibir dimensiones que están más allá de la escala en la cual operan nuestros sentidos, lo cual se traduce en una ceguera respecto al efecto agregado o de sumatoria de nuestras conductas aisladas como actores individuales. El campesino que desmonta una hectárea de bosque nativo en cualquier lugar del mundo es ignorante e inconsciente de que son miles de campesinos quienes en forma aislada hacen lo mismo cada día en todo el mundo. Algo parecido le ocurre a los miles de conductores que deciden salir de paseo cada fin de semana de cualquiera gran aglomeración urbana y que encuentran con enormes concentraciones de vehículos en las autopistas con personas que persiguen algo similar. Posiblemente muchos de nosotros hemos vivido la experiencia de descubrir una forma de evitar los cotidianos trancones o tacos de tránsito y nos hemos encontrado con sorpresa al cabo de unos días que tal forma de evasión ya no es tal pues son cientos o miles quienes han descubierto y hacen lo mismo.

Gregory Bateson nos ha enseñado que la conciencia requiere para operar o para activarse del surgimiento de quiebres. En situaciones en las cuales el cambio es progresivo y constante, vale decir, en las que por cada 
unidad de tiempo la progresión en términos de unidades de cambio es similar, nuestros sentidos no alcanzan a percibir dicha transformación, pues lo que percibimos preponderantemente es la constancia de la transformación. Es lo que le sucede a una rana que puesta dentro de una olla con agua fría y puesta ésta al fuego, nunca salta y termina cocida porque sus sentidos no le alertan de ningún quiebre. La progresión de aumento de la temperatura es constante y eso evita el natural estrés que si produce un cambio abrupto.

Los cambios producidos por nuestro impacto sobre el ambiente, si bien a escala local pueden producir quiebres significativos, a nivel agregado terminan siendo de una gradualidad y constancia que nos imposibilita percibirlos. Es lo que nos ocurre a quienes habitamos una localidad y no nos damos cuenta de los cambios que ésta ha experimentado en el tiempo, cosa que si percibe inmediatamente quien la visita después de varios años.

\section{La “creación” compulsiva de deseos ¿necesidades?}

El papel de la publicidad es la creación de necesidades (léase deseos). El crecimiento capitalista se basa en la permanente creación de necesidades, muchas de ellas artificiales, para sostener la demanda por nuevos bienes que es la que lo alimenta. Hace ya más de seis décadas, uno de los estrategas enseñaba su juego con candor: su nombre es Stanley B. Resor, presidente de la J. Walter Thompson, una de las mayores agencias de publicidad de Estados Unidos. Para Resor,

“...cuando aumentan los ingresos, la creación de nuevas necesidades es lo más importante. Cuando se pregunta a la gente: «¿Sabe usted que su nivel de vida aumentará en un 50 por ciento en los próximos 10 años?», no tienen la menor idea de lo que eso quiere decir. No reconocen la necesidad de un segundo coche a menos que se les recuerde con insistencia. Esta necesidad tiene que ser creada en su ánimo y es preciso hacerles ver las ventajas que les procurará el segundo coche. Yo considero la publicidad como la fuerza de educación y de activación capaz de provocar los cambios de la demanda que nos son precisos”. ${ }^{3}$

La sociedad capitalista actual ancla su existencia en la producción industrial de bienes de consumo masivo: bienes que requieren ser permanentemente desvalorados y desechados, para así continuar creando nuevos bienes que los sustituyan. Gorz expone agudamente este hecho:

"Preocupadas solamente de hacer funcionar la máquina, de hacer circular el capital, de mantener un cierto nivel de empleo, nos fabrican las necesidades correspondientes a las exigencias, en un momento dado, del aparato de producción y de circulación. Nos inventan deliberada y sistemáticamente nuevas escaseces y carencias, nuevos lujos y nuevas pobrezas, conforme a las necesidades de rentabilidad y de crecimiento del capital”. (1989: 128) 
Bauman señala al respecto:

"Se puede decir que el "consumismo" es un tipo de acuerdo social que resulta de la reconversión de los deseos, ganas o anhelos humanos (si se quiere "neutrales" respecto del sistema) en la principal fuerza de impulso y de operaciones de la sociedad, una fuerza que coordina la reproducción sistemática, la integración social, la estratificación social y la formación del individuo humano, así como también desempeña un papel preponderante en los procesos individuales y grupales de auto identificación, y en la selección y consecución de políticas de vida individuales”. (2007: 47)

Gorz concluye que es el consumidor el que está al servicio de la producción, para así asegurar a ésta las salidas que reclama; que es el consumidor quien tiene que irse adaptando a los requerimientos de las producciones que los cambios tecnológicos indican como las más rentables en determinadas circunstancias. Afirma por otra parte, que ello es indispensable para que la sociedad pueda perpetuarse, y así reproducir sus desigualdades jerárquicas y mantener incólumes sus mecanismos de dominación.

\section{La incapacidad de reconocer la principal de las eficiencias: la eficiencia reproductiva de la vida}

Franz Hinkelammert ha denunciado en diversos trabajos la incapacidad del sistema capitalista para reconocer la principal eficiencia: la eficiencia reproductiva de la vida. Mientras que la racionalidad capitalista apunta a la construcción del mercado "total" que debería guiar "todas" las acciones del ser humano mediante relaciones mercantiles. Su lógica lo abarca "todo". La ética del mercado total gira sobre un valor central: la eficiencia. Si los individuos logran alcanzar sus fines específicos con la menor cantidad posible de medios, entrarán en las esferas de la productividad y, por ende, tendrán la posibilidad de competir en el mercado. La eficiencia se transforma así en el valor supremo que decide sobre la validez de "todos" los demás valores. De tal modo que instituciones como la propiedad privada y el derecho contractual en cuanto sustento de la eficiencia son considerados los valores centrales de la institucionalidad existente. Estos valores son la base para desarrollar la cultura en que el individuo pueda alcanzar sus fines específicos con la máxima eficiencia posible. No importando los medios utilizados para obtener los fines propuestos, aunque así se impida la reproducción de la vida misma. Es una racionalidad irracional que no permite criterios valorativos sobre sus hechos. Se introducen cambios pero sin modificar su funcionamiento básico, excepto su velocidad.

\section{El temor a la escasez}

Los seres humanos a lo largo de nuestra historia evolutiva hemos ensayado diversas formas de dar cuenta de nuestras necesidades, todas ellas sin embargo han requerido de una forma de relación con la naturaleza y con los otros, que hiciera posible la apropiación de los recursos. En las socieda- 
des sin clases del pasado y en algunas que todavía sobreviven, la forma de apropiación fue predominantemente social o colectiva. Es la sociedad capitalista la que para su desarrollo requirió, como condición necesaria, la eliminación de toda forma de apropiación que no fuese individual. De modo tal que el capitalismo globalizado en el cual hoy vivimos ha terminado por reducir a su mínima expresión, todos aquellos que fueron bienes comunes en el pasado.

El capitalismo ha configurado un imaginario anclado en la creencia en la escasez como la condición dominante en el ámbito de la economía y desde allí ha contaminado todos los ámbitos de la existencia humana. Al considerar la escasez como un principio casi equivalente al principio de realidad, los seres humanos nos vemos obligados, casi compulsivamente, a acumular todo aquello que teñimos con el atributo de la escasez, y a defender lo acumulado haciendo uso de todos los recursos de los cuales disponemos. «Además como vivimos en una cultura centrada en la apropiación, vivimos de la apropiación, y en ella aprendemos a querer, a desear y a necesitar cosas que nos son en lo fundamental superfluas, pero dependemos de ellas, de modo que si no se nos dan vivimos en la escasez, y aparece el stress en el miedo continuo de perder o no lograr acumular las posesiones que se desea obtener porque las posesiones se viven como fuentes de seguridad.» (Maturana 1991:63). En la sociedad capitalista llega a ser considerado casi anormal o patológico el compartir, cuando la emoción del compartir fue una condición constitutiva de la evolución de nuestra condición de primates a humanos. (Maturana, 1995)

Asimismo, esta visión condujo a una invisibilización de amplios segmentos de la realidad que tornó invisibles todos aquellos recursos que por su naturaleza son abundantes y por los cuales los seres humanos no necesitan competir, sesgando por ende nuestra percepción de la realidad y destacando en ella únicamente aquellos recursos que por su naturaleza son escasos. De tal manera, incluso, se contagió con el atributo de la escasez a los recursos que abundan, y aún más, también a los que para crecer requieren de manera imprescindible ser compartidos. Operó de tal modo un verdadero enmascaramiento de la realidad, un proceso de ideologización y de creación de una falsa conciencia.

De este modo la economía capitalista ha colonizado lo abundante transformándolo en escaso y haciéndolo económico lo torna visible, por medio de la mercantilización y la privatización. Ya no es más posible el acceso gratuito y libre a lo abundante, como lo era antes de ser colonizado. Esto era necesario para permitir que se llevasen a cabo aquellos cambios fundamentales en la vida social, tales como el inicio y desarrollo de los procesos de acumulación en gran escala, y el surgimiento del capital, que se constituyó así en la más enorme fuerza transformadora de la existencia del hombre que ha operado en la historia. Ello implicaba la necesidad de producir una ruptura total de las formas de organización de la convivencia humana reguladas por la búsqueda de la simetría y la cooperación, y la violación de la escala humana en las relaciones entre los seres humanos. 
Esta ideología de la escasez tiñó la realidad de tal modo que empujó a los hombres hacia la competencia en vez de la cooperación, al logro del lucro y del beneficio por sobre la minimización del riesgo, a la búsqueda de certezas en el tener por encima del ser. Los seres humanos nos hemos visto así empujados a expresar nuestra identidad mediante el consumo. Son los bienes a los cuales podemos acceder los que nos hacen presentes en un mundo en el cual la apariencia, esto es la forma como nos manifestamos ante otros, se ha ido transformando en la expresión privilegiada de la condición humana.

\section{Una perspectiva utópica}

Orlando Fals Borda, en uno de sus últimos trabajos publicados augura (utopiza) algunos de los instrumentos heurísticos que nos pueden hacer posible avanzar hacia un nuevo paradigma:

"Por fortuna, la llegada del nuevo siglo coincide con la disponibilidad de novedosas herramientas analíticas del tipo abierto que se derivan de saberes consolidados de diversa índole. Al combinarlas acá, con buen juicio crítico, pueden ayudarnos a entender las dimensiones complejas, y regulares, multilineales y fractales de nuestras estructuras tropicales, así sociales, naturales. En esta forma sumatoria, teorías de europeos sobre complejidad y sistemas (P. B. Checkland, Ernst Mayr) se enriquecen con las de Maturana o con las de los indígenas Desana (circuitos de la biosfera) estudiados por Reichel; la teoría del caos (Mandelbrot, Prigonine) se refresca con los estudios de la cotidianeidad de la colega venezolana Jeannette Abuabara; la cosmovisión participativa de Meter Reason se contextualiza con la utopía participativa de Camilo Torres; el holismo de Bateson y Capra encuentra apoyo en pensadores orientales y aborígenes. Se perfila así una alianza de colegas del norte y del sur en la que podemos tomar parte motivados por los mismos problemas e impulsados por intereses similares, una alianza entre iguales que logre corregir en todas partes los defectos estructurales e injusticias del mundo contemporáneo.” (2002:35-36)

Asimismo desde la experiencia acumulada por varias décadas de aplicación de su propuesta metodológica, nos presenta como un horizonte posible y alcanzable para el trabajo académico una propuesta en la cual hacer converger nuestro pensar, nuestro operar y nuestros valores:

"Si logramos que converjan la praxis, la frónesis y el ethos, y colocamos esta combinación en una perspectiva de fusión de horizontes, obtendremos además otras dos ganancias: 1) seríamos más efectivos, persistentes y certeros en nuestro trabajo, al constatar que el propósito de nuestro conocimiento, como fenómeno fluido, es guiar y gobernar mejor nuestra acción cotidiana; y 2) nos acercaríamos a la construcción de paradigmas que fueran práctica, intelectual y moralmente satisfactorios.” (1998:253) 

altruismo:

Y nos presenta como el valor central inspirador de esta búsqueda al

"Necesitamos volver los ojos otra vez a la Estrella Polar del altruismo, y permitirle al altruismo ejercer todo su potencial subversivo en el descompuesto mundo contemporáneo. En esta forma más o menos grandiosa, hacer que lo instrumental converja con lo axiológico -tener la cabeza lúcida y corazón de león- es un esfuerzo útil para redefinir y reconectar nuestras disciplinas y artes, y para recobrar el sentido positivo de nuestras preocupaciones científicas y prácticas.” (1998:254) 


\section{Notas}

${ }^{1}$ Ecoportal.net 06/12/11 Ribeiro, Silvia. «Los verdaderos colores de la economía verde». Disponible en: http://www.ecoportal.net/Temas_Especiales/Economia/Los_verdaderos _colores_de_la_economia_verde

${ }^{2}$ Samuelson, Paul A. 26/10/2008 Adiós al capitalismo de Friedman y Hayek” disponible en: http://www.elpais.com/articulo/primer/plano/Adios/capitalismo/Friedman/Hayek/ elpepueconeg/20081026elpneglse_6/Tes

${ }^{3}$ Citado por André Gorz en Adiós al proletariado, Imago Mundi, Buenos Aires, 1989, págs. 127 y 128. 


\section{Bibliografía}

Asimov, Isaac (1973), “Introducción a la Ciencia”, Basic Books, Plaza \& Janes S.A. Editores, Madrid.

Bateson, Gregory (1990), Espíritu y naturaleza, Amorrortu, Buenos Aires.

Bauman, Zygmunt (2001), En busca de la política, Fondo de Cultura Económica, Buenos Aires.

Ídem (2007), Vida de consumo, Fondo de Cultura Económica de Argentina, Buenos Aires.

Capra, Fritjof (2003), Las conexiones ocultas. Implicaciones sociales, medioambientales, económicas y biológicas de una nueva visión del mundo, Anagrama, Barcelona.

Catton, William R., Jr. (2010) Rebasados. Las bases ecológicas para un cambio revolucionario, Editorial Oceáno, México D.F.

Cortina, Adela (2002), Por una Ética del Consumo. La ciudadanía del consumidor en un mundo global, Taurus, Madrid.

Fals Borda, Orlando (1998), Participación popular. Retos del futuro, ICFES/ IEPRI/COLCIENCIAS, Bogotá.

Fals Borda, Orlando y Mora-Osejo, Luis Eduardo (2002), “La superación del Eurocentrismo. Enriquecimiento del saber sistémico y endógeno sobre nuestro contexto tropical” en Polis. Revista de la Universidad Bolivariana, N 7, Santiago, pp. 29-39. Disponible en: Polis [En línea], 7 | 2004, Puesto en línea el 07 septiembre 2012, consultado el 16 noviembre 2012. URL : http://polis.revues.org/6210 ; DOI : 10.4000/polis.6210

García Roca, Joaquín. (1990), El Dios de la fraternidad, Ediciones Salterrae, Santander.

Gorz, André (1989), Adiós al proletariado, Imago Mundi, Buenos Aires.

Feyerabend, Paul (1986), Tratado contra el método, Tecnos, Madrid.

Hinkelammert, Franz (1989), La Fe de Abraham y el Edipo Occidental, Editorial DEI, San José de Costa Rica.

Lipovetsky, Gilles (2007), La felicidad paradójica. Ensayo sobre la sociedad de hiperconsumo. Anagrama, Barcelona.

Maturana, Humberto (1991), El sentido de lo humano, Hachette, Santiago. Ídem (1995), La realidad: ¿objetiva o construida? I. Fundamentos bioló- 
gicos de la realidad. Anthropos, Barcelona

Sennett, Richard (2006), La cultura del nuevo capitalismo, Editorial Anagrama, Barcelona.

Solow, Robert (1994) "La economía de los recursos o los recursos de la economía” en De la Economía Ambiental a la Economía Ecológica, Federico Aguilera Klink y Vicent Alcántara (comp.), ICARIA/FUHEM, Madrid.

Varela, Francisco (1996), Ética y Acción, Dolmen Ediciones, Santiago.

Váquez Espí, Mariano (2008), “¿Tiene solución la ciudad?” en Polis, Vol. 7 N²0. Disponible en: Polis [En línea], 20 | 2008, Puesto en línea el 19 julio 2012, consultado el 17 noviembre 2012. URL : http://polis.revues.org/ 3485; DOI : 10.4000/polis.3485

Recibido: 15.10.2012

Aceptado: 07.11.2012 